\title{
Cross-Elasticities in Frequencies and Ridership for Urban Local Routes
}

\author{
Joseph C. Totten and David M. Levinson, Ph.D. \\ University of Minnesota-Twin Cities
}

\begin{abstract}
Observational data from the Minneapolis-Saint Paul region's Metro Transit were analyzed to determine the effects of service levels on ridership levels at different intervals. The research compares changes in service levels and ridership in several service intervals and includes elasticities and cross elasticities, or the influence that these service levels have on different service intervals' ridership. These cross-elasticities were found to have little effect during the week; however, weekend ridership was found to be influenced by rush-hour and overnight frequencies.
\end{abstract}

Keywords: Bus transit, scheduling, elasticity

\section{Introduction}

Most people in the U.S. do not ride public transportation, specifically local buses. It has been posited that one factor is due to flexibility: although services for rush hour may be adequate, there is little flexibility for return trips at non-standard times (Jaffe 2014; Dutch 2015). This study investigated these assertions, with the hypothesis that if a common reason for not riding transit is a lack of flexibility, an increase in midday and/ or evening services would increase rush-hour ridership. This was done by determining elasticities of ridership with respect to frequencies of bus routes. Elasticities signify the percent change in ridership that results from a $1 \%$ change in frequency; a cross-elasticity is the elasticity of a service interval's ridership with respect to another interval's frequency. This research is important because it informs transit providers about how they can best use their limited resources to garner ridership. The routes examined in this study were local routes, primarily within the Minneapolis and St. Paul city limits, with pre-existing midday and evening services. The routes examined and their general changes in frequency are shown in Figure 1. 


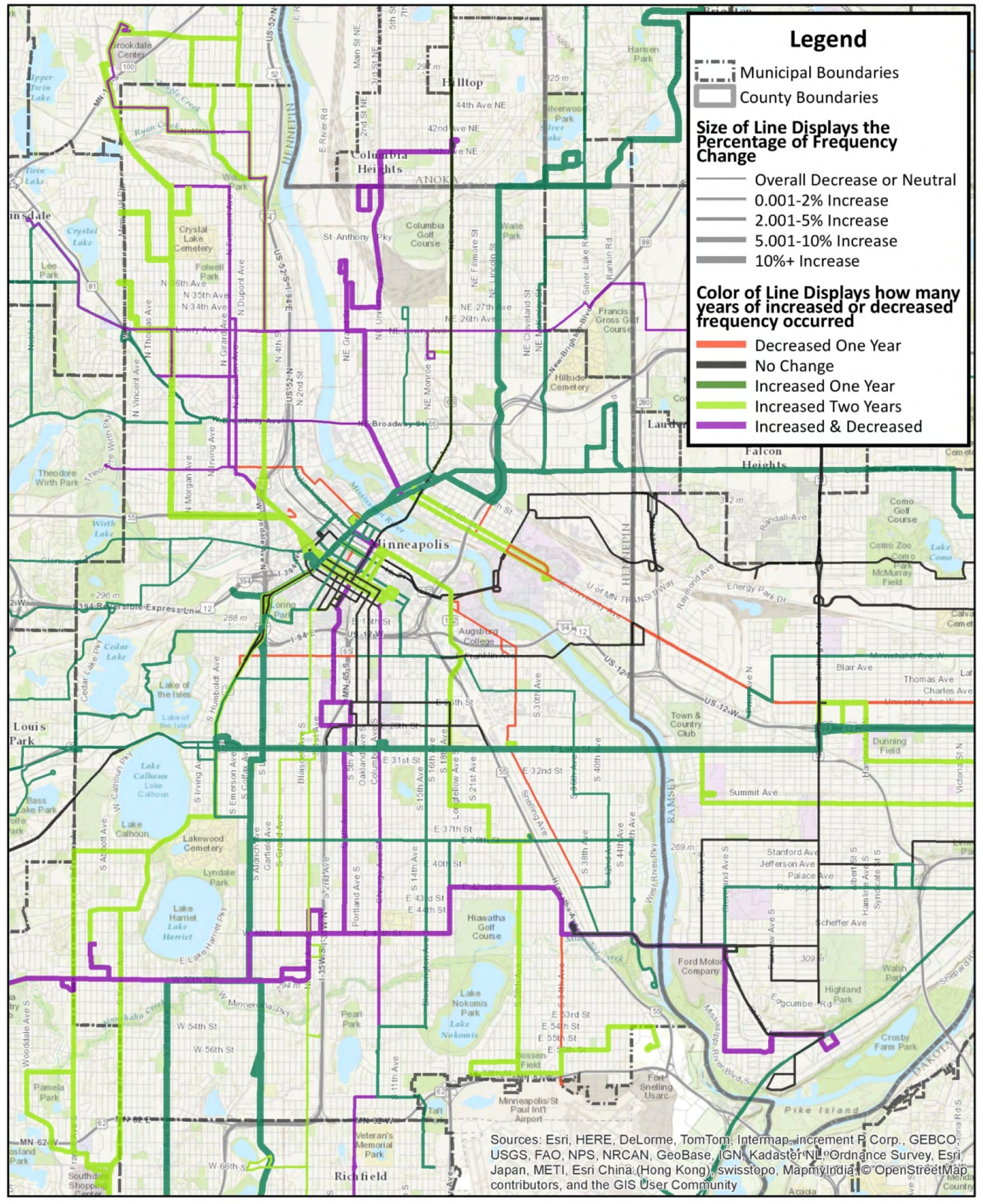

FIGURE 1. Map of urban-local bus routes and frequency change, Minneapolis 


\section{Literature Review}

The studies shown in Table 1 are primarily literature reviews and analysis of existing studies. The values shown and discussed in this study focus on short-term elasticities, with year-over-year changes in ridership and service levels. Previous works on the effect of frequency on ridership have found that frequency has an elasticity between 0.30 and 1.03 (Evans 2004). The lower value is a better representation of urban systems, the higher value is more related to suburban systems with infrequent service. Furthermore, on weekends, when there is less-frequent service in metropolitan transit, higher elasticities are observed than on weekdays (Paulley et al. 2006). As a proxy for the influence of increasing service levels, service expansion or increasing the hours that a service is offered also has been studied (Simmons 2014), with findings that expanding evening service had an elasticity of 0.30 to 0.50 while equivalent increases occur during the day (Currie and Loader 2009). Studies regarding the frequency of off-peak service and its effect on ridership during other service periods were not found by the author.

TABLE 1.

Previous Study Results

\begin{tabular}{|l|c|c|l|}
\hline \multicolumn{1}{|c|}{ Study Author } & Year(s) & Range & \multicolumn{1}{c|}{ Locations Studied } \\
\hline Evans & 2004 & $0.30-1.03$ & North America, Europe \\
\hline Currie and Loader & 2009 & $0.17-0.38$ weekday 0.80+ weekends & Melbourne, Australia, \\
\hline Litman & 2015 & $0.50-0.70$ & $\begin{array}{l}\text { North America, Western } \\
\text { Europe }\end{array}$ \\
\hline Paulley et al. & 2006 & 0.38 & Europe \\
\hline Brown and Neog & 2012 & $0.76-0.91$ & United States \\
\hline Koonce et al. & 2006 & $0.30-1.11$ & Portland, Oregon \\
\hline Lago et al. & 1981 & $0.30-0.85$ & North America, London \\
\hline
\end{tabular}

\section{Methods}

Data were collected by Metro Transit of Minneapolis-St. Paul, Minnesota, for the fall quarters of three years $(2011,2012,2013)$ and include the number of runs started each hour and ridership figures for weekday, Saturday, and Sunday service, with weekday ridership divided into rush-hour ridership and non-rush-hour ridership. Only data from local and limited-stop routes were used, as these routes were less susceptible to changes in routing while still providing changes in scheduling. Making the raw data usable for this analysis required taking the runs started each hour and averaging them for each service interval to get each service interval's average runs per hour in each year. Additionally, the percent change of every service interval's data needed to be taken for 2011 to 2012 and 2012 to 2013. The equation used for percent change in frequency is:

$$
\Delta_{F}=\left(\frac{F_{t}-F_{t-1}}{F_{t-1}}\right) * 100 \%
$$

Where $\Delta_{F}$ is the percent change of hourly frequency for the service interval from one year to the next and $F_{\mathrm{t}}$ is the hourly frequency for the service interval in year $\mathrm{t}$. 
The equation used for percent change in ridership is:

$$
\Delta_{R}=\left(\frac{R_{t}-R_{t-1}}{R_{t-1}}\right) * 100 \%
$$

Where $\Delta_{R}$ is the percent change of ridership from one year to the next and $R_{\mathrm{t}}$ is the ridership in year $\mathrm{t}$.

To investigate the hypothesis, elasticities and cross-elasticities were studied. Elasticity is used when both the dependent and independent variables vary over time and can be expressed in percent changes. The value of elasticity is the coefficient of percent change of the independent variable to produce the dependent variable, as seen in the following equation:

$$
\Delta_{R}=\Delta_{F} * E
$$

Where $\Delta_{R}$ is the percent change of ridership, $\Delta_{F}$ is the percent change of frequency, and $E$ is the elasticity.

As this study aimed to determine elasticities not only during the same hours, but also across hours, both own-elasticities and cross-elasticities were evaluated. An ownelasticity is when the dependent variable of ridership and the independent variable of frequency are represented in the same time period; a cross-elasticity has variables representing different time periods. Because elasticities were considered as a coefficient in a linear relationship, the regression used was a Robust Standard Error Linear regression, to minimize the effect of outliers.

Table 2 shows the times of each service interval and how ridership data were compiled.

TABLE 2.

Hours of Ridership and Service Interval Data

\begin{tabular}{|l|l|l|}
\hline \multicolumn{1}{|c|}{ Hours } & \multicolumn{1}{c|}{ Ridership Data } & Service Data \\
\hline 01:00-05:00 & Non-Rush Hour & Owl \\
\hline 06:00-09:00 & Rush Hour & Rush Hour \\
\hline 09:00-15:00 & Non-Rush Hour & Midday \\
\hline 15:00-18:30 & Rush Hour & Rush Hour \\
\hline 18:30-01:00 & Non-Rush Hour & Evening \\
\hline Saturday & Saturday & Saturday \\
\hline Sunday & Sunday & Sunday \\
\hline
\end{tabular}

${ }^{1}$ 05:00 was not used in any service interval and was ignored for this analysis.

2 8:00 is split between rush hour and evening service; therefore, any runs starting between 18:00 and 18:59 were considered half a run in rush hour and half a run in evening service.

${ }^{3}$ Weekend frequencies consist of runs from 08:00-21:00 to isolate changes in frequency, as opposed to service-hour expansion. 


\section{Results}

Whereas 120 route-years are displayed, only 80 elasticity measurements (including zeroes) were included due to needing two route-years to get one elasticity measurement. The lack of data points for owl service levels, as seen in Table 3, make it difficult to make a strong claim about any significance using this service interval. Table 3 shows there are high standard deviations for frequencies, as compared to average frequencies; this indicates the diversity of local bus routes in the Minneapolis-Saint Paul metropolitan area. Some routes require many buses per hour, such as Route 5 , with a frequency of 8.75 buses per hour or 7-minute headways during rush hour; some require a much lower level of service, such as Route 62 with a frequency of 1.08 per hour and nearly 1-hour headway during rush hour.

TABLE 3.

Descriptive Statistics

\begin{tabular}{|l|c|c|c|c|c|}
\hline $\begin{array}{c}\text { Frequency } \\
\text { Time } \\
\text { Frame }\end{array}$ & $\begin{array}{c}\text { Number of } \\
\text { Route-Years } \\
\text { with Any } \\
\text { Service }\end{array}$ & $\begin{array}{c}\text { Number of } \\
\text { Route-Years } \\
\text { with at Least } \\
\text { Hourly Service }\end{array}$ & $\begin{array}{c}\text { Number of } \\
\text { Changes in } \\
\text { Frequency }\end{array}$ & $\begin{array}{c}\text { Average } \\
\text { Frequency of } \\
\text { Routes with } \\
\text { Service }\end{array}$ & $\begin{array}{c}\text { Standard } \\
\text { Deviation of } \\
\text { Frequency of } \\
\text { Routes with } \\
\text { Service }\end{array}$ \\
\hline Rush Hour & 120 & 114 & 35 & 3.91 & 2.10 \\
\hline Midday & 111 & 102 & 19 & 3.48 & 2.02 \\
\hline Evening & 99 & 76 & 20 & 1.87 & 1.00 \\
\hline Owl & 78 & 3 & 4 & 0.42 & 0.31 \\
\hline Saturday & 96 & 82 & 18 & 2.94 & 1.62 \\
\hline Sunday & 90 & 75 & 21 & 2.30 & 1.19 \\
\hline
\end{tabular}

1 If a route's frequency changed from one year to the next for the service period shown, then that would be one change in frequency. Thus, this represents the number of data points actually used for determining elasticity.

As seen in Table 4, the percent change of ridership is very highly-correlated between Saturday and Sunday ridership, with a lesser correlation in scheduling. As shown, Saturday and Sunday are similar, but are still different enough that they should be considered separately, as they are in the analysis. In Table 5, all ridership correlations are positive, indicating that if ridership increases in one service period, it generally increases in other periods.

TABLE 4.

Correlation Matrix of Percent Change in Ridership

\begin{tabular}{|l|r|r|r|r|r|}
\hline & Saturday & Sunday & Off Peak & Peak & Weekday Total \\
\hline Saturday & 1 & 0.8334 & 0.0851 & 0.0478 & 0.1240 \\
\hline Sunday & & 1 & 0.0998 & 0.0835 & 0.1318 \\
\hline Off Peak & & & 1 & 0.4261 & 0.5850 \\
\hline Peak & & & & 1 & 0.9261 \\
\hline Weekday Total & & & & & 1 \\
\hline
\end{tabular}


TABLE 5.

Correlation Matrix of Percent Change in Frequency

\begin{tabular}{|l|r|r|r|r|r|r|}
\hline & Rush Hour & Midday & Evening & Owl & Saturday & Sunday \\
\hline Rush Hour & 1 & 0.4725 & -0.0111 & -0.0344 & -0.0233 & -0.0557 \\
\hline Midday & & 1 & 0.0585 & -0.0316 & 0.0066 & 0.0347 \\
\hline Evening & & & 1 & 0.57694 & -0.0835 & 0.0987 \\
\hline Owl & & & & 1 & 0.0485 & 0.0160 \\
\hline Saturday & & & & & 1 & 0.7339 \\
\hline Sunday & & & & & & 1 \\
\hline
\end{tabular}

For rush-hour ridership, as shown in Table 6, it can be seen that rush hour is the only service level that has an elasticity significant at $p<0.10$. Rush-hour frequency has a strong positive elasticity with ridership. The found elasticity of 0.39 falls in the normal range, as shown in the literature review, for short-term elasticity. The influences of the frequencies of other schedule periods were not seen to be significant in this study. No service period had an effect significant at $\mathrm{p}<0.05$ on rush hour ridership.

TABLE 6.

Results

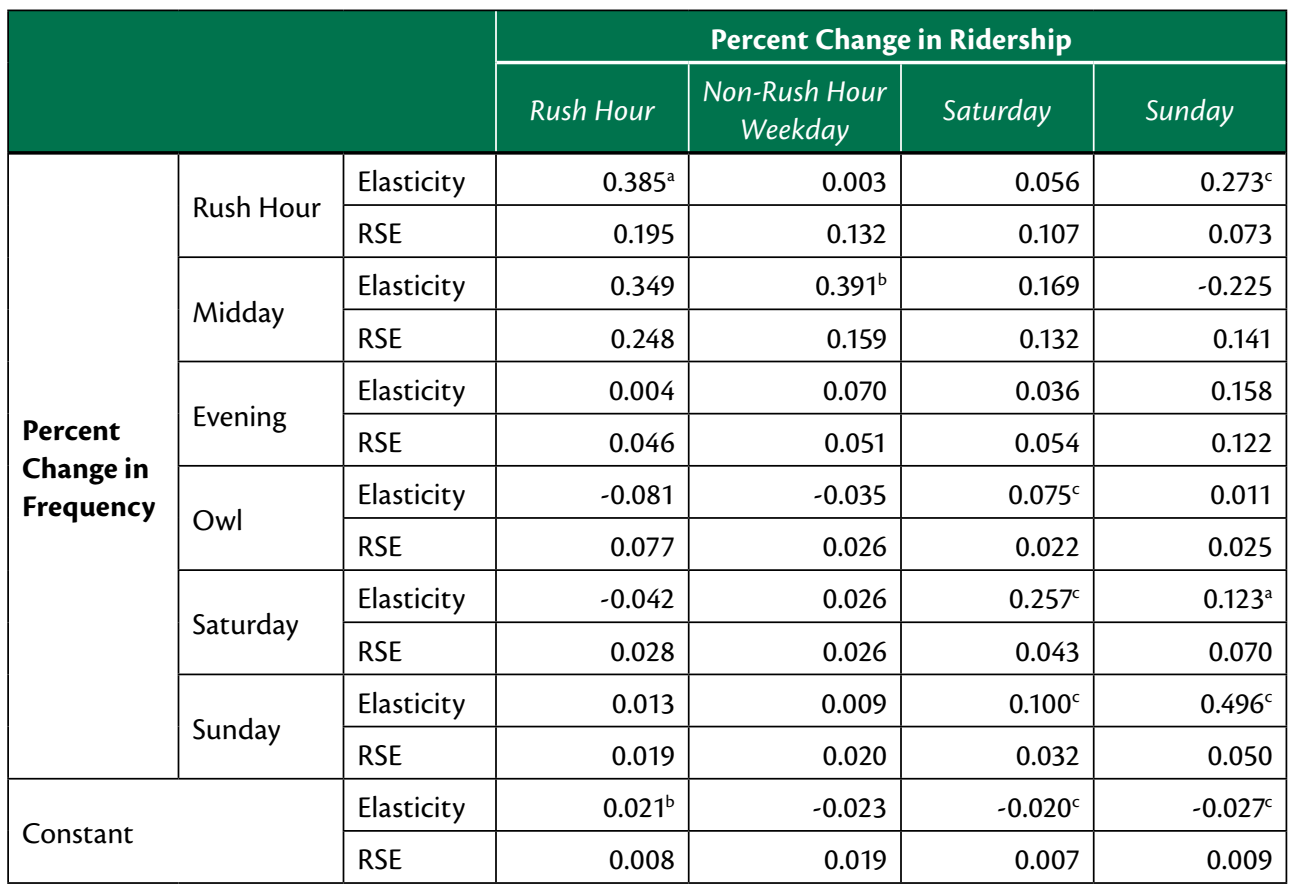

${ }^{a}|p|<0.10$

${ }^{\mathrm{b}}|p|<0.05$

c $|p|<0.01$

For non-rush hour weekday ridership, as shown in Table 6, midday frequency has an elasticity of 0.39 , which is significant at $p<0.05$. Whereas non-rush hour weekday ridership contains midday, evening, and owl service within its defined times, midday frequencies had an effect that would put it in line with the own-elasticities found in previous studies. No other service intervals were seen as being significant at $p<0.10$ for non-rush hour weekday ridership. Further research with ridership data for each service interval would allow for more accurate and useful results for all service intervals. 
As shown in Table 6, weekend and owl service intervals have elasticities significant at $p<0.10$ with Saturday ridership, whereas Saturday and owl service are significant at $p<0.01$ and Sunday service is significant at $p<0.05$. This is likely associated with Saturday ridership comprising riders using both Saturday service and owl service on Friday night after midnight. The own-elasticity seen for Saturday service of 0.26 is lower than expected compared to previous studies. The effect of Sunday service on Saturday ridership is posited as due to the weekend being observed as one entity to most of the traveling public and possibly the correlation of 0.7339 between Saturday and Sunday frequencies. The magnitude of the Sunday elasticity is not great, at 0.10. The low elasticity value of owl frequency, at 0.08 , and the small number of changes in owl frequency, as seen in Table 3, make this result questionable, as there are not enough data to make a strong claim.

Significant elasticities for Sunday ridership at $p<0.10$, as shown in Table 6, were seen with rush hour, Saturday, and Sunday service intervals. Sunday and rush-hour frequencies are significant at $p<0.01$. Sunday's own-elasticity was seen as 0.50 , and rush hour's services had an elasticity of 0.27 on Sunday ridership. A possible explanation for why rush hour frequency appears to have a significant effect on Sunday ridership may be due simply to a growing transit mode share along a route, as people may become less averse to using transit for weekend travel if they use it for their daily commuting needs. Saturday frequency had a smaller effect on Sunday ridership, with an elasticity of only 0.12 . As with Saturday ridership, the correlation between Saturday and Sunday changes in frequency are a possible factor in these elasticities; more data are needed with changes in these service intervals to know if they are truly affecting one another or simply changing together.

\section{Conclusion}

This research established that the ridership of weekday service depends on the frequencies of rush hour and midday and refutes the hypothesis that changes in midday and evening frequencies would have a noticeable effect on rush-hour ridership. During the week, rush-hour ridership is seen as being affected by changes of only rush-hour frequency, with an elasticity of 0.39 ; likewise, non-peak ridership was seen as affected only by changes in midday frequency, with an elasticity of 0.39 . The weekends are far more interconnected, with service levels during rush hour, owl, and the entire weekend being significant for the ridership on one or both days of the weekend. Saturday ridership was affected by changes in Saturday frequency with an elasticity of 0.26 and Sunday frequency with an elastic of 0.10 ; owl frequency also was seen as a contributor in this analysis, but with so few changes in owl frequency, this cannot be certain. Sunday ridership was affected by changes in Sunday frequencies with an elasticity of 0.50 , Saturday frequencies with an elasticity of 0.12 , and rush-hour frequency with an elasticity of 0.27 . It is intuitive that all own-elasticities and crosselasticities would be positive and cross-elasticities would overall be smaller than ownelasticities. Additionally, the hypothesis of this research failed to be corroborated; if the goal of a transit agency is to provide as many rush-hour trips as possible, this research 
has established that using driver hours at other times is not shown to have any effect, whereas using those driver hours during rush hours will increase ridership.

This research should be expanded to include a larger data set, including express and suburban local routes, and should be replicated in other metropolitan areas. The additional research also would allow for a better determination of significance, as there would be more data to solidify significance or non-significance. Express routes, in particular, should be investigated, as midday and evening service usually is not provided on these routes; thus, adding these services would allow for investigation of new services and elasticities at much lower frequencies.

\section{References}

Brown, J., and D. Neog. 2012. "Central Business Districts and Transit Ridership: A Reexamination of the Relationship in the United States." Journal of Public Transportation, 15(4): 1-22.

Carrel, A., A. Halvorsen, and J. Walker. 2013. “Passengers' Perception of and Behavioral Adaptation to Unreliability in Public Transportation." Transportation Research Record, 2351: 153-62.

Currie, G., and C. Loader. 2009 "High Ridership Growth from Extended Transit Service Hours: An Exploration of the Causes." Transportation Research Record, 2110: 120-127

Dutch, S. 2013. “Why People Don't Use Mass Transit." http://www.uwgb.edu/dutchs/ pseudosc/masstransit.htm, accessed Sep 3, 2015.

Evans, J. E., IV. 2004. “TCRP Report 95: Traveler Response to Transportation System Changes Chapter 9: Transit Scheduling and Frequency." Transportation Research Board of the National Academies, Washington, DC.

Federal Transit Administration. 1998. "Research Results Digest; Continuing Examination of Successful Transit Ridership Initiatives" Transit Cooperative Research Program, Washington, DC.

Jaffe, E. 2014. "If So Many People Support Mass Transit, Why Do So Few Ride?" The Atlantic, 22.

Koonce, Peter, P. Ryus, D. Zagel, Y. Park, and J. Parks. 2006. "An Evaluation of Comprehensive Transit Improvements-TriMet's Streamline Program." Journal of Public Transportation, 9(3): 103-115.

Lago, A., P. Maywork, and J. McEnroe. 1981. "Transit Service Elasticities, Evidence from Demonstration and Demand Models." Journal of Transport Economics and Policy, May: 99-119.

Litman, T. 2014. "Transportation Elasticities: How Prices and Other Factors Affect Travel Behavior." Victoria Transport Policy Institute, http://www.vtpi.org/tdm/tdm11. htm\#_Toc161022588, accessed April 15, 2015. 
Litman, T. 2015. "Transit Price Elasticities and Cross-Elasticities." Victoria Transport Policy Institute, http://www.vtpi.org/tranelas.pdf, accessed September 1, 2015.

McMahon, J. 2013. “Top Eight Reasons People Give Up On Public Transit." Forbes, May 6.

Metropolitan Council. 2015. Data Finder, "Transit Boardings and Alightings." http:// www.datafinder.org/metadata/TransitStopsBoardingsAndAlightings.html, accessed August 7, 2015.

Paulley, N., R. Balcombe, R. Mackett, H. Titheridge, J. M. Preston, M. R. Wardman, J. D. Shires, J. D. and P. White. 2006. "The Demand for Public Transport: The Effects of Fares, Quality of Service, Income and Car Ownership." Transport Policy, 13(4): 295 306.

Simmons, J. 2014. "Bus Route Span of Service Changes: Ridership Impacts on Unaltered Hours." Master's thesis, San Jose State University.

\section{About the Authors}

JOSEPH TOTTEN (totte011@umn.edu) has a BSCE from the University of MinnesotaTwin Cities with an emphasis in transportation and a minor in Urban Studies. He currently works for the City of Edina, Minnesota, in traffic and traffic safety.

DAVID LeVINSON (dlevinson@umn.edu) is the Richard P. Braun/CTS Chair in Transportation in the Department of Civil, Environmental, and Geo-Engineering at the University of Minnesota and director of the Networks, Economics and Urban Systems (NEXUS) research group. He holds a Ph.D. in Transportation Engineering from the University of California at Berkeley. 